2002s-65

\title{
Early or Late Conflict Settlement in a Variety of Games - An Experimental Study -
}

Vital Anderhub, Werner Güth and Nadège Marchand

\begin{tabular}{c}
\hline Série Scientifique \\
Scientific Series
\end{tabular}

Montréal

Juillet 2002

(C) 2002 Vital Anderhub, Werner Güth, Nadège Marchand. Tous droits réservés. All rights reserved. Reproduction partielle permise avec citation du document source, incluant la notice $\odot$.

Short sections may be quoted without explicit permission, if full credit, including $\odot$ notice, is given to the source.
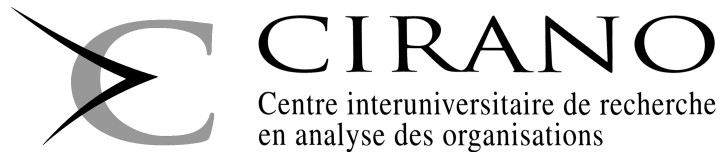

Centre interuniversitaire de recherche en analyse des organisations 


\section{CIRANO}

Le CIRANO est un organisme sans but lucratif constitué en vertu de la Loi des compagnies du Québec. Le financement de son infrastructure et de ses activités de recherche provient des cotisations de ses organisationsmembres, d'une subvention d'infrastructure du ministère de la Recherche, de la Science et de la Technologie, de même que des subventions et mandats obtenus par ses équipes de recherche.

CIRANO is a private non-profit organization incorporated under the Québec Companies Act. Its infrastructure and research activities are funded through fees paid by member organizations, an infrastructure grant from the Ministère de la Recherche, de la Science et de la Technologie, and grants and research mandates obtained by its research teams.

\section{Les organisations-partenaires / The Partner Organizations}

-École des Hautes Études Commerciales

-École Polytechnique de Montréal

-Université Concordia

- Université de Montréal

-Université du Québec à Montréal

-Université Laval

-Université McGill

-Ministère des Finances du Québec

-MRST

-Alcan inc.

-AXA Canada

-Banque du Canada

-Banque Laurentienne du Canada

-Banque Nationale du Canada

-Banque Royale du Canada

-Bell Canada

- Bombardier

-Bourse de Montréal

-Développement des ressources humaines Canada (DRHC)

-Fédération des caisses Desjardins du Québec

-Hydro-Québec

-Industrie Canada

-Pratt \& Whitney Canada Inc.

-Raymond Chabot Grant Thornton

-Ville de Montréal

Les cahiers de la série scientifique (CS) visent à rendre accessibles des résultats de recherche effectuée au CIRANO afin de susciter échanges et commentaires. Ces cahiers sont écrits dans le style des publications scientifiques. Les idées et les opinions émises sont sous l'unique responsabilité des auteurs et ne représentent pas nécessairement les positions du CIRANO ou de ses partenaires.

This paper presents research carried out at CIRANO and aims at encouraging discussion and comment.

The observations and viewpoints expressed are the sole responsibility of the authors. They do not necessarily represent positions of CIRANO or its partners. 


\title{
Early or Late Conflict Settlement in a Variety of Games - An Experimental Study -*
}

\author{
Vital Anderhub ${ }^{\dagger}$, Werner Güth $\dagger$ and Nadège Marchand
}

\begin{abstract}
Résumé / Abstract
La théorie des jeux prédit que la résolution des jeux de négociation séquentielle dépend essentiellement de l'évolution de la rente à partager dans le temps (taux d'escompte), et du pouvoir d'ultimatum de l'offreur à la première période. Nous étudions à l'aide de la méthode expérimentale huit jeux de négociation séquentielle afin d'évaluer l'impact du pouvoir de négociation et du taux d'escompte sur les comportements. Chaque jeu est répété une fois avant de passer à un nouveau jeu, notre test est composé de cycle composé de 16 jeux consécutifs. Les participants ont été confrontés à 3 cycles. Au cours du test, aucun effet d'expérience lié à la répétition des jeux n'a été détecté. Les participants ont adopté un comportement stable et robuste d'anticipation des changements de règle de jeu. Les stratégies mises en œuvre font référence à des considérations, non stratégiques, basées à la fois sur des normes sociales d'équité et d'efficience.

The game theoretic prediction for alternating offer bargaining depends crucially on how "the pie" changes over time, and whether the proposer in an early round has ultimatum power. We experimentally study eight such games. Each game is once repeated before being followed by the next one, which defines a cycle of altogether 16 successive plays. Participants play three such cycles. There are no major experience effects but strong and reliable effects of anticipated rule changes. The latter, however, are not due to strategic considerations but rather to the social norms of fairness and efficiency.
\end{abstract}

Mots clés : Jeux de négociation séquentiels, ultimatum.

Keywords: Alternating bargaining games, ultimatum.

\footnotetext{
* We thank Dorothea Kübler and Claude Montmarquette for helpful comments and two anonymous referees for their constructive advice.

$\dagger$ Humboldt University of Berlin, Department of Economics, Institute for Economic Theory III, Spandauer Str. 1, D-10178 Berlin, Germany.

$\dagger$ Max Planck Institute for Research into Economic Systems, Strategic Interaction Group, Kahlaische Str. 10, D-07745 Jena, Germany.

† Groupe d'Analyse et de Théorie Economique (GATE), UMR 5328 du CNRS, 93, Chemin des Mouilles, 69130

Ecully, France.
} 


\section{Introduction}

Alternating offer bargaining is a familiar topic in experimental economics. Starting with Binmore, Shaked, and Sutton (1985) the late eighties experienced a vivid debate whether and how actual bargaining behavior differs from game theoretic predictions (see Güth, 1995, and Roth, 1995, for surveys). Almost invariably these studies assume a "shrinking pie", namely. that delaying an agreement is costly, for instance due to discounting.

Why does one insist on alternations in proposing? The usual argument is that this is what one observes in reality. Unfortunately, the solution behavior of such bargaining games predicts an immediate agreement, that is it denies that alternating proposals will be observed. One way out of this dilemma is to rely on incomplete information (e.g. Harsanyi and Selten, 1972, or Rubinstein, 1985). Another possibility is to allow also for increasing pies as in our study.

What was varied more systematically before was the time horizon $T$, that is the last period for reaching an agreement, varying from $T=1$ (Güth et al., 1982), $T=2$ (Binmore et al., 1985, Güth and Tietz, 1986, Ochs and Roth, 1989), $T=3$ (Ochs and Roth, 1989), $T=5$ (Neelin et al., 1988) to " $T=\infty$ ", i.e. to not specifying explicitly a final period $T$ (Weg, Rapoport, and Felsenthal, 1990) as suggested by Rubinstein (1982). One major result of these studies is that only for $T=1$ and $T=2$ the implications of backward induction are obvious even when this does not always imply the corresponding behavior. For $T>3$, strategic considerations are more of the forward induction type ${ }^{1}$. Since the influence of the time horizon $T$ has already been thoroughly explored, our experiment always relies on $T=3$.

\footnotetext{
${ }^{1}$ Unlike in game theory where forward induction is used to select among subgame perfect equilibria, e.g. the stability concept of Kohlberg and Mertens, 1986, we use it in a much broader sense, namely as a reasoning idea used to generate a likely or intended play of the game. In alternating offer bargaining for a shrinking pie, one such an idea is, e.g. to demand the difference between the 1st and 2nd round pie in round 1 if this yields more than $50 \%$ of the 1 st round pie.
} 
The fact that parties alternate in proposing an agreement does not necessarily imply that bargaining has to end in the last period $T$ if no earlier agreement is reached. If there is commitment power at all (which is implicitly assumed by all bargaining models), it seems feasible that one can always declare one's offer to be final, that is one has ultimatum power (Güth, Ockenfels, and Wendel, 1993). In our experiment participants confront both situations, namely on where each proposer has ultimatum power and one where bargaining may be stopped early only by an early agreement.

Over time the "pie", that is what can be distributed among the parties, can either decrease or increase. Whereas a shrinking pie reflects the well-known costs of delaying an agreement, such as wasting time, starting too late to cooperate etc., an increasing pie can be justified by the fact that later agreements are often more adequate, for example by being based on more information, superior incentives etc. Here we do not only rely on monotonic developments but also explore a "hill" (the "pie" is largest in period 2) and a "valley" (the "pie" is lowest in period 2). A vector $\left(p_{1}, p_{2}, p_{3}\right)$ of pies $p_{\mathrm{t}}$ in periods $t=1,2,3$ is numerically specified for each of the four (the two monotonic and the two non-monotonic) different "pie"-developments.

What motivates studying non-monotonic pie-developments in the form of "hills" and "valleys"? Clearly, there can be situations when there is just one point in time for striking a deal, for instance when opportunity costs of the deal are exceptionally high. Our main motivation, however, has been a theoretical one: In case of a "valley" one may want to strike the deal either in the first or in the last round. Participants who failed in reaching an early agreement may thus want to signal their intentions for a late agreement by their choices in the intermediate round. A "hill", on the other hand, suggests avoiding an early as well as a late agreement. Thus, the first round can be used for signaling one's intentions whereas the last rounds offers the opportunity to punish the other participant when failing to reach an intermediate agreement.

Each of the four vectors $\left(p_{1}, p_{2}, p_{3}\right)$ is first played twice with and then twice without ultimatum power. Thus, participants first learn to play a usual alternating offer game 
before commanding ultimatum power already in the earlier periods ( $t=1$ and $t=2$ ). We refer to the altogether 16 games ( 4 vectors $\left(p_{1}, p_{2}, p_{3}\right) \times 4$ successive plays) as a cycle. Participants play three such cycles, that is altogether 48 bargaining games.

How behavior is influenced by past results is intensively studied, both theoretically (in evolutionary game theory and economics) and experimentally (see Roth and Erev,1995, for a selective overview). By letting participants play the same simple or more complex (e.g. Huck, Normann, and Oechsler, 1999) game many times, one observes how behavior adapts to previous experiences in an otherwise constant environment. Here we also study such "behavioral adaptation" but restrict experiences with the same game to 6 plays and with the same vector $\left(p_{1}, p_{2}, p_{3}\right)$ to 12 plays.

Contrary to many theoretical models of behavioral adaptation (see Weibull, 1995, for a survey), boundedly rational decision making is influenced by past experiences (the shadow of the past) and by deliberating the likely consequences of the various choice alternatives (the shadow of the future). Especially boundedly rational decision makers should deliberately react to a changing environment, by switching from one of the eight games to another. "Robust learning experiments" (see Güth, 2000, for a comparison with other studies) do not study behavior in one game but in a variety of related games. The idea is to collect evidence for learning (in the sense of improving behavioral parameters in the light of past experiences) and for cognitive adjustments when confronting a new situation. In the light of such evidence one can hopefully model how learning and forward looking deliberation interact in a process of boundedly rational decision emergence. Unlike perfect rationality, bounded rationality should be based on sound empirical facts rather than abstract axioms. The former can be provided by explorative and hypotheses testing (robust learning) experiments.

With this background in mind, we can summarize the main intentions of our experimental study: 
- We want to establish (stylized) facts and a data basis illustrating how boundedly rational negotiators learn from previous experiences with the same or a closely related bargaining game.

- We want to demonstrate that the likely consequences of bargaining behavior are anticipated, but not in a perfectly rational way, as suggested by backward induction, but rather in a norm-guided way. More specifically, we want to show that strategic aspects which are crucial for the game theoretic solutions do not matter much behaviorally. Thus, orthodox game theory has to be complemented by a behavioral theory of (here bargaining) game playing.

- If the largest "pie" requires delaying an agreement, efficiency (in the sense of reaching an agreement when the pie is largest) requires a lot of trust that one will not be exploited. Our experimental data should reveal whether the fear of being exploited questions efficiency and whether such a fear is justified.

Our results are straightforward: Participants mostly reach an agreement when the pie is largest and they share this pie rather equally (slightly favoring the proposer in this period). Especially in case of universal ultimatum power this often contradicts game theory. Partly unfair offers are used to discourage inefficient agreements. Regarding the first two aspects, this shows that learning is of no or little importance and that, in simple environments like ours, norm-guided deliberation is crucial.

In the section 2 below we introduce the eight games and their benchmark solutions. Section 3 is devoted to details of the experimental procedure. Section 4 describes the main results, and section 5 statistically corroborates them. Section 6 concludes. 


\section{The game variety}

Two bargaining parties, players 1 and 2, alternate in proposing an agreement which the other can then accept or reject. Acceptance ends the game with the proposed payoff distribution, a vector $\left(u_{1}, u_{2}\right)$ with $p_{\mathrm{t}} \geq u_{1}, u_{2} \geq 0$ and $u_{1}+u_{2}=p_{\mathrm{t}}$ where the pie $p_{\mathrm{t}}$ is what can be distributed in period $t=1,2$, 3. If $t<T$ and the offer $p_{\mathrm{t}}-d_{\mathrm{t}}$ to the other party ( $d_{\mathrm{t}}$ is what the proposer demands for him- or herself) is not an ultimatum, rejection leads to period $t+1$ where $p_{\mathrm{t}+1}$ can now be allocated by the rejecting party. If $t=T$ or if, for $t<T$, the offer $p_{\mathrm{t}}-d_{\mathrm{t}}$ is an ultimatum, rejection implies conflict with each party that receives 0 -payoff. Acceptance, of course, implies that the proposer receives $d_{\mathrm{t}}$ and the responder $p_{\mathrm{t}}-d_{\mathrm{t}}$. In period

$$
\begin{aligned}
& t=1 \text { : player } 1 \text { chooses } d_{1} \text {, i.e. } 1 \text { proposes, } 2 \text { responds, } \\
& t=2 \text { : player } 2 \text { chooses } d_{2} \text {, i.e. } 2 \text { proposes, } 1 \text { responds, } \\
& t=3 \text { : player } 1 \text { chooses } d_{3} \text {, i.e. } 1 \text { proposes, } 2 \text { responds. }
\end{aligned}
$$

If one disregards different individual time preferences, as for instance studied by Ochs and Roth (1989), the "pie"-development for $T=3$ can be described by the vector $\left(p_{1}, p_{2}, p_{3}\right)$ of "pies" $p_{\mathrm{t}}$ specifying in German Marks (DM) what can be distributed in period $t=1,2,3$. We rely on the four vectors $\left(p_{1}, p_{2}, p_{3}\right)$ listed in Table II.1.

\begin{tabular}{|c|c|c|c|c|}
\hline$p_{1}$ & $p_{2}$ & $p_{3}$ & nickname & symbol \\
\hline 30 & 20 & 10 & decline & $D$ \\
10 & 20 & 30 & increase & $I$ \\
10 & 25 & 10 & hill & $H$ \\
25 & 10 & 25 & valley & $V$ \\
\hline
\end{tabular}

Table II.1: The four "pie"-developments

Each of the four vectors $D, I, H$ and $V$ can be played with proposers having ultimatum power, the games $D^{\mathrm{y}}, I^{\mathrm{y}}, H^{\mathrm{y}}$, and $V^{\mathrm{y}}$, or not, the games $D^{\mathrm{n}}, I^{\mathrm{n}}, H^{\mathrm{n}}$, and $V^{\mathrm{n}}$. 
For each of the four vectors $D, I, H$, and $V$ (the four rows in Table II.2) the left column of Table II.2 describes the (subgame perfect equilibrium, see Selten, 1975) solution demands $\left(d_{1}^{*}, d_{2}^{*}, d_{3}^{*}\right)$ and their payoff implications $u_{1}^{*}$ and $u_{2}^{*}$ for players 1 and 2 when only integer offers are possible and an indifferent responder always rejects. If ultimatum power is available, it will always be used, i.e. each proposal $d_{\mathrm{t}}^{*}$ for $t=1,2,3$ and the games $D^{\mathrm{y}}, I^{\mathrm{y}}, H^{\mathrm{y}}$, and $V^{\mathrm{y}}$ is an ultimatum. Thus with ultimatum power bargaining always stops in period $t=1$ whereas this is true only for $D$ if no ultimatum power is available. The period $t^{*}$ in which the agreement is reached ${ }^{2}$ is indicated in Table II.2 by fat demands $d_{\mathrm{t}}^{*}$. Whereas in the $n$-games $D^{\mathrm{n}}, I^{\mathrm{n}}, H^{\mathrm{n}}$, and $V^{\mathrm{n}}$ the outcome is always efficient in the sense that $u_{1}^{*}$ and $u_{2}^{*}$ add up to the maximal "pie", this is only true for the $y$-games $D^{\mathrm{y}}$ and $V^{\mathrm{y}}$ when $p_{1}$ is largest.

\begin{tabular}{|l|c|c|c|c|c|c|c|c|c|c|}
\hline \multirow{3}{*}{$\left(p_{1}, p_{2}, p_{3}\right)$-type } & \multicolumn{10}{|c|}{$n(\mathrm{o})$} \\
\cline { 2 - 11 } & $d_{1}^{*}$ & $d_{2}^{*}$ & $d_{3}^{*}$ & $u_{1}^{*}$ & $u_{2}^{*}$ & $d_{1}^{*}$ & $d_{2}^{*}$ & $d_{3}^{*}$ & $u_{1}^{*}$ & $u_{2}^{*}$ \\
\hline$D=(30,20,10)$ & 19 & 10 & 9 & 19 & 11 & 29 & 19 & 9 & 29 & 1 \\
$I=(10,20,30)$ & 10 & 20 & 29 & 29 & 1 & 9 & 19 & 29 & 9 & 1 \\
$H=(10,25,10)$ & 10 & 15 & 9 & 10 & 15 & 9 & 24 & 9 & 9 & 1 \\
$V=(25,10,25)$ & 24 & 10 & 24 & 24 & 1 & 24 & 9 & 24 & 24 & 1 \\
\hline
\end{tabular}

Table II.2: The solution demands $d_{1}^{*}, d_{2}^{*}, d_{3}^{*}$ and payoffs $u_{1}^{*}, u_{2}^{*}$ for the eight different games $D^{\mathrm{y}}, I^{\mathrm{y}}, H^{\mathrm{y}}, V^{\mathrm{y}}$ and, respectively, $D^{\mathrm{n}}, I^{\mathrm{n}}, H^{\mathrm{n}}, V^{\mathrm{n}}$

\section{Experimental procedure}

The computerized experiment involved 6 sessions, 5 with 12 participants and 1 with 10. Participants, mostly students of economics or business administration of Humboldt University, Berlin, were invited by leaflets to register for the experiment. They were

\footnotetext{
${ }^{2}$ The agreement period $\mathbf{t}^{*}$ for game $\mathbf{V}^{\mathrm{n}}$, where player $\mathbf{1}$ can achieve the same agreement in periods 1 and 3, is left ambiguous in spite of our requirements (according to our assumptions player 2 should reject the first offer and accept the second in period $t=3$ where acceptance is the only best reply).
} 
seated at visually isolated terminals where they found the written instructions (see Appendix A for an English translation). After reading them carefully participants could privately ask for clarifications. Then the experiment started with the first cycle.

A cycle consisted of two plays of $D^{\mathrm{n}}$, followed by two plays of $D^{\mathrm{y}}$, and continuing with this pattern for the vector $I, H$, and $V$ with four plays each. This cycle of altogether 16 rounds was twice repeated. After each round participants were randomly rematched without switching roles (of players 1 and 2, respectively). Thus, a participant usually confronted six different partners in an irregular fashion. Average earnings were DM 32.9 including the DM 5.0 show-up fee. A session took about 110 minutes (30 minutes for reading the instructions and answering questions). More detailed information about monetary payoffs is contained in Table IV.1 where earnings are separated according to role (players 1 and 2), game type, and cycle.

\section{Results}

A coarse way of searching for experience effects is to compare the average relative (to the maximal pie) earnings of both players for the three cycles (see Table IV.1 which distinguishes by roles, 1 or 2 , cycle $\left(1^{\text {st }}, 2^{\text {nd }}, 3^{\text {rd }}\right)$, pie-vector $(D, I, H, V$, all $)$ and $n(o)$ or $y(e s)$ ultimatum power). Relative earnings are surprisingly constant over the three cycles when proposers command no ultimatum power. We only found significant differences in the $y$-games' relative earnings between cycles. ${ }^{3}$ When comparing relative earning variations in and between cycles, we found significant increases only for the Decline pie-development with ultimatum power (between the $1^{\text {st }}$ cycle (rounds 3 and 4) and the $3^{\text {rd }}$ cycle (rounds 35 and 36) and between these two cycles $p=.0008$, Binomial test, one-tailed, for all tests).

\footnotetext{
${ }^{3}$ Statistically one compares for $\mathrm{i}=1,2$ the differences in average relative (to the maximal pie) earnings between cycles separately for each of the four games (with ultimatum power) with individual plays as observations. These test results are, of course, questionable since they assume independence in spite of repeated interaction. In our view, such test results are nevertheless informative. We will partly test treatment effects more convincingly by using matching group averages as independent observations.
} 
For the $n$-games the distribution of relative earnings in the $3^{\text {rd }}$ cycle is not significantly different from those in cycles 1 and 2 with $p=.479$ for player 1 (Wilcoxon Matched-Pairs Signed Ranks Test, one-tailed) and, respectively $p=.479$ for player 2 . For the $y$-games one obtains significant differences with $p=.0001$ and $p=.0001$ for players 1 and. 2, respectively. This suggests

\begin{tabular}{|cc|ccc|ccc|ccc|}
\hline \hline \multirow{2}{*}{ Cycles } & & \multicolumn{3}{|c|}{ Role 1 } & \multicolumn{3}{c|}{ Role 2 } & \multicolumn{3}{c|}{ Both Roles } \\
& & 1st & 2nd & 3rd & 1st & 2nd & 3rd & 1st & 2nd & 3rd \\
\hline \hline \multirow{2}{*}{ Decline } & $\mathrm{n}$ & .47 & .44 & .49 & .43 & .40 & .45 & .45 & .42 & .47 \\
& $\mathrm{y}$ & .41 & .49 & .49 & .35 & .41 & .42 & .38 & .45 & .45 \\
\hline Increase & $\mathrm{n}$ & .45 & .49 & .49 & .41 & .43 & .43 & .43 & .46 & .46 \\
& $\mathrm{y}$ & .33 & .45 & .43 & .29 & .38 & .37 & .31 & .41 & .40 \\
\hline \multirow{2}{*}{ Hill } & $\mathrm{n}$ & .42 & .41 & .41 & .50 & .49 & .50 & .46 & .45 & .46 \\
& $\mathrm{y}$ & .34 & .35 & .36 & .41 & .47 & .46 & .38 & .41 & .41 \\
\hline Valley & $\mathrm{n}$ & .47 & .48 & .48 & .40 & .40 & .41 & .44 & .44 & .44 \\
& $\mathrm{y}$ & .42 & .40 & .48 & .34 & .33 & .39 & .38 & .36 & .44 \\
\hline All games & $\mathrm{n}$ & .45 & .45 & .47 & .43 & .43 & .45 & .44 & .44 & .46 \\
& $\mathrm{y}$ & .38 & .42 & .44 & .35 & .40 & .41 & .36 & .41 & .43 \\
\hline \hline
\end{tabular}

Table IV.1: Average earnings as shares of $\max \left\{p_{1}, p_{2}, p_{3}\right\}$ separated by game type, role, and cycle (including conflicts)

Observation 1: Unlike in games without early veto power where efficient conflict settlements dominate right from the start participants in games with early veto power achieve such agreements only when becoming more experienced. Average earnings are affected by the conflict rate, the period of reaching an agreement, and the payoff distribution which is accepted.

The first aspect is illuminated in Table IV.2 listing the agreement and, respectively, conflict ratios as well as their absolute numbers (for the three cycles) separately for the $n(o)$ and the $y(e s)$-games and the periods $t=1,2,3$. Most agreements occurred when 
the periodic pie is largest (in case of " $V$ (alley)" this applies to the $1^{\text {st }}$ and $3^{\text {rd }}$ periods). Remember that game theory excludes conflict and predicts agreement for games with the largest periodic pie except for the games $I^{\mathrm{y}}$ and $H^{\mathrm{y}}$ (see Table II.2). The agreement ratios in Table IV.2 thus imply

Observation 2: Agreement is mostly achieved when the pie is largest, which partly (for games $I^{\mathrm{y}}$ and $H^{\mathrm{y}}$ ) rejects game theory. ${ }^{4}$

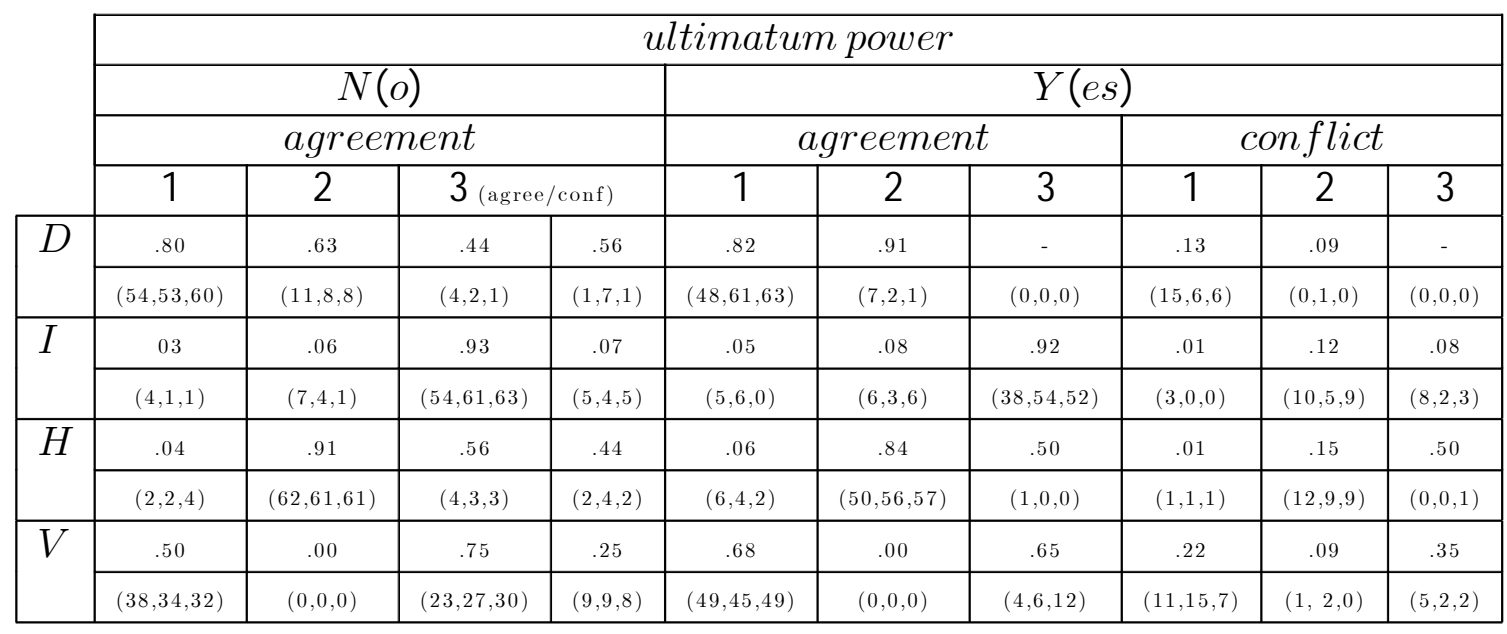

Table IV.2: Conditional probability of reaching an agreement or of conflict (only for ultimatum power) in period $t$ (total number of $1^{\text {rst }}, 2^{\text {nd }}, 3^{\text {rd }}$ cycle in brackets).

There are, however, non-negligible numbers of conflicts, namely, 28 for $D^{\mathrm{y}}, 40$ for $I^{\mathrm{y}}$, 34 for $H^{\mathrm{y}}$, and 45 for $V^{\mathrm{y}}$ when proposers have ultimatum power (for no ultimatum power the frequencies of conflict are 9 for $D^{\mathrm{n}}, 14$ for $I^{\mathrm{n}}, 6$ for $H^{\mathrm{n}}$ and 26 for $\left.V^{\mathrm{n}}\right)$. Conflict frequency often, but not always, decreases with experience, as measured by cycle (see conflict frequencies in brackets, Table IV.2). Unlike the $n$-games, conflicts in $y$-games can result earlier or later: like agreements they result more frequently in period $t$ when $p_{\mathrm{t}}$

\footnotetext{
${ }^{4}$ What is actually rejected is commonly known rationality with respect to one's own material success. Allowing for idiosyncratic preferences (how can those be commonly known?) risks rendering rationality as tautological.
} 
is largest, that is when one would have expected a fair offer. More specifically, comparing the conflict ratios in games $D^{\mathrm{y}}$ and $V^{\mathrm{y}}$ (where $p_{1}$ is largest) with those in games $I^{\mathrm{y}}$ and $H^{\mathrm{y}}$ yields significant differences $(p=.047$ Wilcoxon Matched-Pairs Signed Ranks Test, one-tailed, for $D^{\mathrm{y}}$ versus $I^{\mathrm{y}}$ and $p=.023$ for $V^{\mathrm{y}}$ versus $\left.H^{\mathrm{y}}\right) .{ }^{5}$

Observation 3: Conflict occurs most frequently in the $1^{\text {st }}$ period of games with ultimatum power only for game types $D^{\mathrm{y}}$ and $V^{\mathrm{y}}$ when the $1^{\text {st }}$ pie is largest (for the other $y$-games conflict is delayed). Without ultimatum power the pie-development $V$ inspires the most conflicts (in all three cycles).

Since efficiency of agreements depends only weakly on the level of experience (as measured by cycle), Table IV.3 provides a fair overview of the efficiency rate

$$
\delta=\frac{u_{1}+u_{2}}{\max \left\{p_{1}, p_{2}, p_{3}\right\}}
$$

of agreements for all eight game types (cases of conflict are excluded). Ultimatum power of proposers hardly affects efficiency of agreements even in games $I^{\mathrm{y}}$ and $H^{\mathrm{y}}$ where the game theoretic benchmark solution predicts $\delta=\frac{1}{3}$ and, respectively, $\delta=\frac{2}{5}$. Also, the differences between pie-dynamics are minor $(\leq .07)$.

Usually. the agreed upon distributions slightly favor the player who is the proposer for the largest pie, as revealed by player 1's payoff shares

$$
s=\frac{u_{1}}{u_{1}+u_{2}}
$$

of agreements listed in Table IV.3. Only the pie-dynamics " $H$ (ill)" with player 2 as the proposer when the pie is largest yields a share $s<.5$. If one compares the $s$-share in games $H^{\mathrm{n}}$ and $H^{\mathrm{y}}$ with that of the other games, the (negative) difference is highly significant; similar comparisons between the other games reveal no significant effects. This is qualitatively in line with the benchmark solution for $H^{\mathrm{n}}\left(\right.$ with $\left.s^{*}=.4\right)$. Altogether, the results in Table IV.3 suggest

\footnotetext{
${ }^{5}$ We only compare those two games whose maximal pie-values are the same.
} 
Observation 4: Agreements are nearly always efficient, i.e., reached in period $t$ when $p_{\mathrm{t}}$ is largest, and slightly favor (by a not more than $5 \%$ deviation from the equal split) the proposer in that period $t$.

\begin{tabular}{|l|l|l|}
\cline { 2 - 3 } \multicolumn{1}{c|}{} & \multicolumn{1}{c|}{$N(o)$} & $Y(e s)$ \\
\cline { 2 - 3 } \multicolumn{1}{c|}{} & $(\delta, s)$ & $(\delta, s)$ \\
\hline$D$ & $(.93, .52)$ & $(.98, .54)$ \\
\hline$I$ & $(.96, .53)$ & $(.93, .54)$ \\
\hline$H$ & $(.95, .46)$ & $(.96, .45)$ \\
\hline$V$ & $(1, .54)$ & $(1, .55)$ \\
\hline
\end{tabular}

Table IV.3 : Efficiency and relative payoff distributions $\delta$ and $s$ when conflict is avoided.

\begin{tabular}{|l|cccc|c|c|c|c|c|c|c|}
\hline \multirow{3}{*}{$\left(p_{1}, p_{2}, p_{3}\right)$-type } & \multicolumn{10}{|c|}{ ultimatum power } \\
\cline { 2 - 12 } & \multicolumn{9}{|c|}{$n(\mathrm{o})$} & \multicolumn{7}{|c|}{$y(\mathrm{es})$} \\
\cline { 2 - 11 } & $d_{1}$ & $d_{2}$ & $d_{3}$ & $u_{1}$ & $u_{2}$ & $d_{1}$ & $d_{2}$ & $d_{3}$ & $u_{1}$ & $u_{2}$ \\
\hline$D=(30,20,10)$ & 16.5 & 11.2 & 6.7 & 14 & 12.8 & 16.9 & 9.5 & & 13.8 & 11.7 \\
$I=(10,20,30)$ & 8 & 13.2 & 16.2 & 14.3 & 12.6 & 8 & 12.9 & 16.2 & 12 & 10.5 \\
$H=(10,25,10)$ & 7.3 & 13.8 & 5.9 & 10.3 & 12.4 & 7.3 & 14.4 & 7 & 8.8 & 11.2 \\
$V=(25,10,25)$ & 14.3 & 7.0 & 14 & 11.9 & 10 & 14.1 & 6.8 & 13.9 & 10.8 & 8.8 \\
\hline
\end{tabular}

Table IV.4: The average demands and payoffs observed for the eight games $D^{\mathrm{y}}, I^{\mathrm{y}}, H^{\mathrm{y}}$, $V^{\mathrm{y}}$ and, respectively, $D^{\mathrm{n}}, I^{\mathrm{n}}, H^{\mathrm{n}}, V^{\mathrm{n}}$ (fat entries when $p_{\mathrm{t}}$ is largest)

Table IV.4 corresponds to Table II.2 and documents that participants are much fairer than the theory predicts. More specifically, in our data file extreme allocations with $u_{2}^{*}=$ 1 are completely avoided. For the $n$-games the actual results are at least qualitatively in line with the effects, as suggested by the benchmark solution. ${ }^{6}$ In $y$-games where the benchmark solution always predicts meager offers $\left(p_{\mathrm{t}}-d_{\mathrm{t}}=1\right)$ it cannot account at all for the actual behavior. Minor differences are due to the differences in conflict ratios and in degrees of missing an agreement when the pie is largest.

\footnotetext{
${ }^{6}$ That most agreements for $\mathrm{V}^{\mathrm{n}}$ are reached in period $\mathrm{t}=1$ only questions the special assumption for the case of indifference.
} 
According to Table IV.4 the average offers in the direction of the period with the maximal pie can be quite meager: thus the average demands $d_{1}$ in period 1 for the vector $I$ are at $80 \%$ of $p_{1}$ are rather unfair; for period 2 at $66 \%$ for $I^{\mathrm{n}}$ and $64.5 \%$ for $I^{\mathrm{y}}$, they are still above the level of $54 \%$ in period 3 when the pie is maximal. Also for the vector $H$ the average demand in period 1 at $73 \%$ is much higher than the average demanded share of 55.2\% (for $H^{\mathrm{n}}$ ) and, respectively 57.6\% (for $H^{\mathrm{y}}$ ) in period 2 with the largest pie. The average demanded shares $d_{2}$ for the vector $V$ are slightly more moderate (70 $\%$ for $V^{\mathrm{n}}, 68 \%$ for $\left.V^{\mathrm{y}}\right)$. Also, after missing an agreement for the largest pie (in periods $t=2$ and 3 for $D$ and in period $t=3$ for $H$ ) the offers are quite generous.

Observation 5: The desire to reach an agreement when the pie is largest is signaled and, respectively, induced by meager offers in earlier periods, both in $n$-games and in $y$-games (in the latter an additional signal is, of course, not to use ultimatum power).

The last observation is corroborated by Figure IV.1 which plots the relative offers at periods $t=1,2,3$. The bold line links the relative offers made when the pie is largest (here, unlike in Table IV.3, the rejected offers are included). For the largest pie-periods mean relative offers stay within the narrow interval [.38; .47], whereas the mean relative offers for given rounds $t$ fluctuate a lot. Participants who fail to reach an agreement at the highest pie- period ( $D$ and $H$ games) often propose higher relative counter offers in the next period (in $31.25 \%$ of cases). 


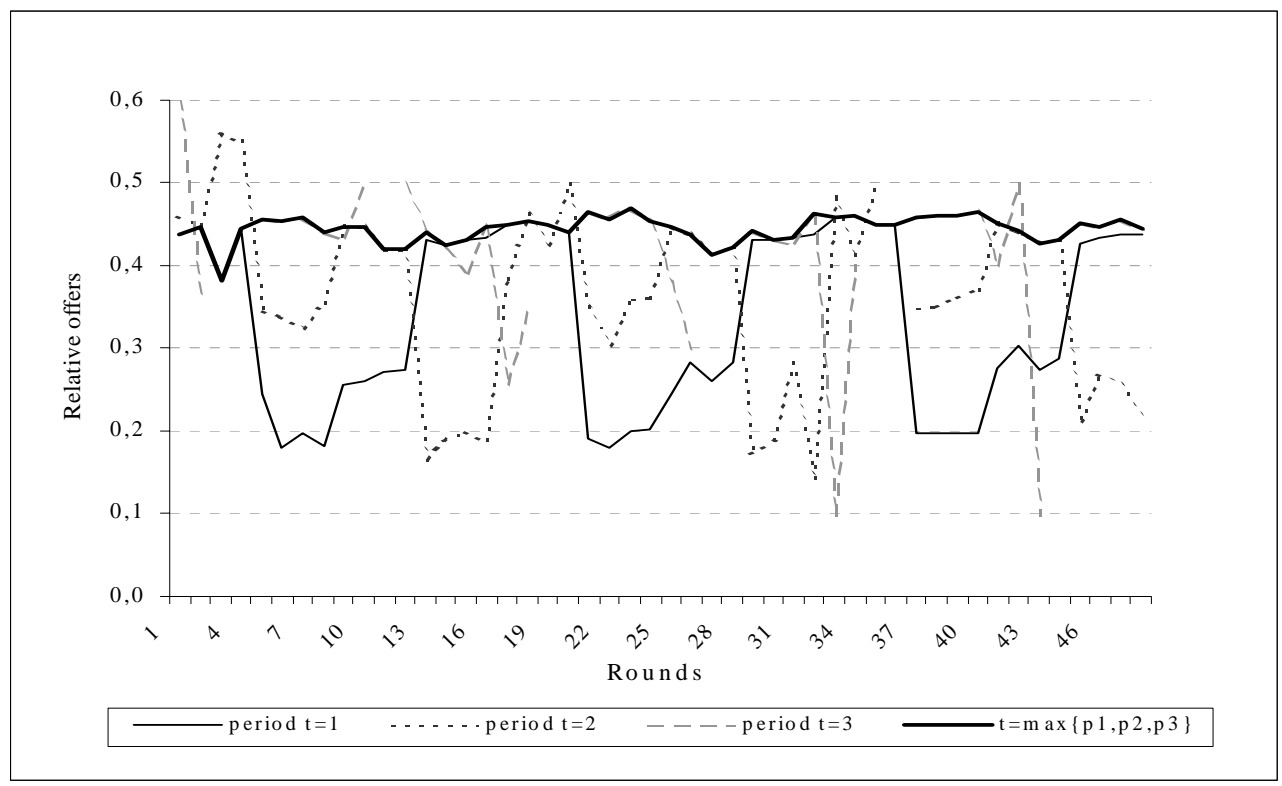

Figure IV.1: Average relative offers at period $t=1,2,3$ and $t=\max \left\{p_{1}, p_{2}, p_{3}\right\}$ over rounds

The ways in which an agreement can be reached when $p_{\mathrm{t}}$ is largest differ for $n-$ and $y$-games. In an $n$-game the proposer in that period $t<3$ must suggest (to the responder in $t$ ) an acceptable distribution of $p_{\mathrm{t}}$. In a $y$-game the proposer can additionally exclude any further possibility to reach an agreement by declaring the offer to be final. Do proposers in $y$-games rely on the same mechanism as in $n$-games? Table IV.5 displays the rates (and the absolute numbers) of exercising one's ultimatum power separately for $t=1$ and $t=2$ (in $t=3$ every offer is an ultimatum offer), the four pie-developments, and each cycle. Around $70 \%$ of the offers $p_{\mathrm{t}}-d_{\mathrm{t}}$ when $p_{\mathrm{t}}$ is largest are ultimatum offers. Thus, ultimatum power is not just neglected but consistently used:

Observation 6: Contrary to game theory, ultimatum power is not always exercised, but mainly used to encourage acceptance when $p_{\mathrm{t}}$ is largest. 
Altogether, our data suggest that commitment power, here in the sense of ultimatum power, is largely overrated in game theory. At least the desire to strive for fair and efficient agreements seems to be much more influential than assumed. This conclusion is supported by Table IV.4 listing average payoffs (which never differ by more than 2.5, i.e. $\left.\left|u_{1}-u_{2}\right|<2.5\right)$.

\begin{tabular}{|c|c|c|c|c|c|}
\hline \multirow{2}{*}{} & & \multicolumn{2}{|c|}{ Mean } & \multicolumn{2}{c|}{ Frequency of ultimatums } \\
\cline { 2 - 6 } \multicolumn{2}{c|}{ cycle } & $t=1$ & $t=2$ & $t=1$ & $t=2$ \\
\hline \multirow{5}{*}{$D$} & 1 & .70 & .33 & 98 & 14 \\
& 2 & .73 & .16 & 102 & 6 \\
& 3 & .67 & .04 & 94 & 2 \\
\cline { 2 - 6 }$I$ & All & .70 & .17 & 294 & 22 \\
\hline \multirow{5}{*}{$H$} & 1 & .06 & .23 & 8 & 30 \\
& 2 & .00 & .11 & 0 & 16 \\
& 3 & .00 & .17 & 0 & 24 \\
\cline { 2 - 6 } & All & .02 & .17 & 8 & 70 \\
\hline \multirow{5}{*}{$H$} & 1 & .01 & .62 & 2 & 86 \\
& 2 & .01 & .71 & 2 & 98 \\
& 3 & .03 & .74 & 4 & 100 \\
\cline { 2 - 6 }$V$ & All & .02 & .69 & 8 & 284 \\
\hline \multirow{5}{*}{$V$} & 1 & .59 & .03 & 82 & 2 \\
& 2 & .60 & .07 & 84 & 4 \\
& 3 & .50 & .00 & 70 & 0 \\
\cline { 2 - 6 } All & All & .56 & .03 & 236 & 6 \\
\hline \multirow{3}{*}{ All } & 1 & .34 & .36 & 190 & 132 \\
& 2 & .34 & .33 & 188 & 124 \\
& 3 & .30 & .32 & 168 & 126 \\
\hline
\end{tabular}

Table IV.5: Termination options (rates and frequencies) chosen at periods $t=1,2$.

Let $S$ denote the share of $p_{\mathrm{t}}$ which has been offered. In general, a low share $S$ should go along with a high rejection rate. Offering a low share $S$ must, however, must not necessarily mean an attempt to exploit the responder. If $p_{\mathrm{t}}$ is not the largest pie, it may simply be a signal to wait for the larger pie. In Figure IV.6 $a$ and $b$ we illustrate for $n-$ and $y$-games as well as for the largest and non-largest pies the frequencies of rejected 
offers for different intervals for $S$, namely $0 \leq S \leq .17, .17<S \leq .33, .33<S<.5, .5 \leq$ $S \leq .5, .5<S$. Clearly, the usual relation between the fairness and acceptability of $S$ holds only for the largest pie-periods.

Observation 7: Only in the largest pie-period does the rejection rate decrease with the relative share $S$ which has been offered

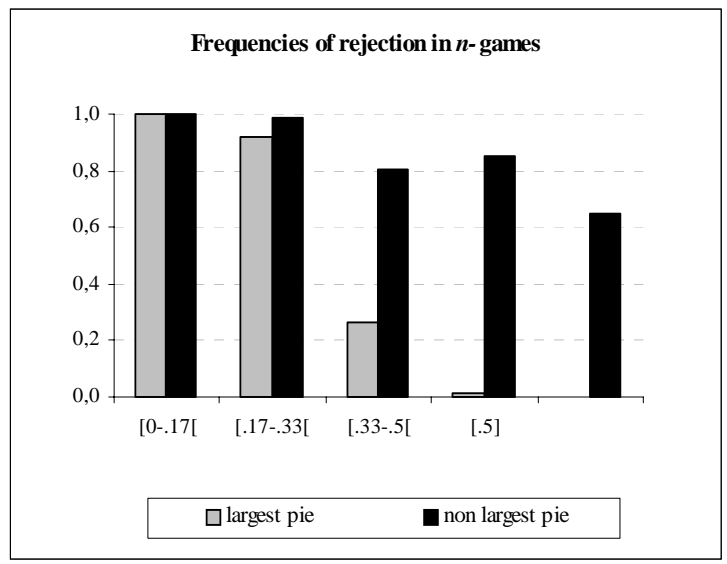

Figure IV.6 a

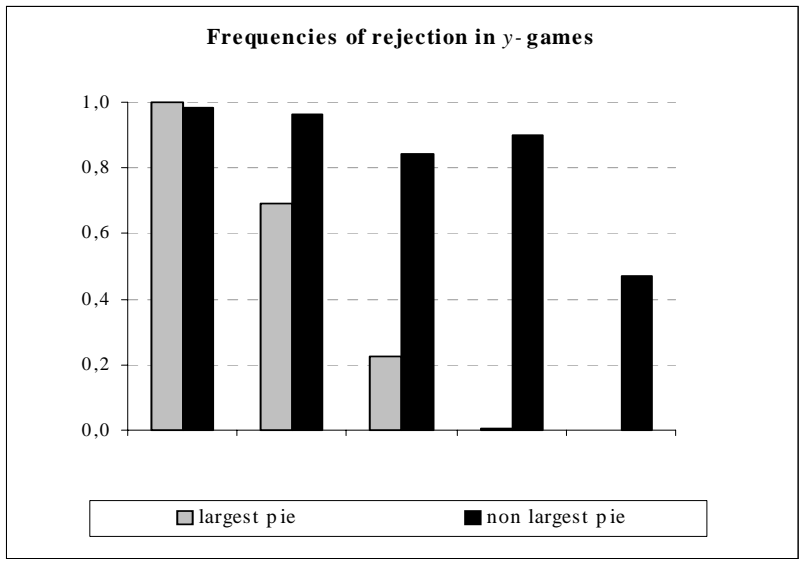

Figure IV.6 b

\section{Further statistical analysis}

To illustrate how the previous observations are supported by our data, we have run a linear regression explaining the offer behavior. The offer made to subject $i$ at period $t$ with $i=1, \ldots, 70$ and $t=1,2,3$ is estimated by the following equation ${ }^{7}$ :

$O_{\mathrm{it}}=\gamma_{0}+\left(\gamma_{1}+\gamma_{1}^{\prime} \cdot T_{\mathrm{it}}^{\mathrm{M} a x}\right) P_{\mathrm{it}}^{\mathrm{M} \mathrm{ax}}+\gamma_{2} P_{\mathrm{it}} \cdot T_{\mathrm{it}}^{\mathrm{noM} a x}+\gamma_{3} T_{\mathrm{it}}^{\mathrm{erm}}+\left(\gamma_{4}+\gamma_{4}^{\prime} \cdot T_{\mathrm{it}}^{\mathrm{M} a x}\right) R_{\mathrm{i}, \mathrm{t}}+\gamma_{5} A_{\mathrm{it}}^{\mathrm{fter}}$

The variable $P_{\mathrm{it}}^{\mathrm{M}}$ ax is the largest pie, i.e. $P_{\mathrm{it}}^{\mathrm{M} \text { ax }}=\max \left\{p_{1_{\mathrm{it}}}, p_{\mathrm{i}_{\mathrm{t}}}, p_{\mathrm{it}_{\mathrm{t}}}\right\} \cdot T_{\mathrm{it}}^{\mathrm{M} \text { ax }}\left(T_{\mathrm{it}}^{\mathrm{noM} \text { ax }}\right)$ represents a dummy variable taking value $1(0)$ if $P_{\mathrm{it}}$, the pie for which subject $i$ makes

\footnotetext{
${ }^{7}$ As participants alternate their position of proposer and responder during the round, offer $\mathrm{O}_{i t}$ is made by participants in role 1 at periods $t=1$ and $t=3$, and by participants in role 2 for $t=2$.
} 
an offer at period $t$, is (not) largest and $0(1)$ otherwise. $T_{i, t}^{\mathrm{erm}}$ is also a dummy variable with $T_{\mathrm{it}}^{\mathrm{erm}}=1$ for $y$-games and $T_{\mathrm{it}}^{\mathrm{erm}}=0$ for $n$-games. Variable $R_{\mathrm{i}, \mathrm{t}}$ indicates the round corresponding to observation $O_{\mathrm{it}} . A_{\mathrm{it}}^{\mathrm{fter}}$ is a dummy variable with value 1 when period $t$ follows the largest pie-period and 0 otherwise. In case of the pie-development $D$ one would have $A_{\mathrm{it}}^{\mathrm{fter}}=1$ for $t=2$ and in case of $H$, for $t=3$.

To test the significance of Observation 5 that efficient agreements are induced by meager offers in early periods parameter $\gamma_{1}$, estimating the influence of $P_{\mathrm{it}}^{\mathrm{M}}$ ax , should be significantly negative and parameter $\gamma_{1}^{\prime}$, concerning the combined effect of $P_{\mathrm{it}}^{\mathrm{M}}$ ax, significantly positive. Since Observation 6 claims that the termination option is not used to exploit but rather to reach an efficient agreement, the influence of the termination option on offers should be negative but insignificant. Furthermore, this should not significantly increase the number of conflicts. To trace learning effects we analyze separately the influence of time $R_{\mathrm{it}}$ on offers when the pie is largest $\left(\gamma_{4}^{\prime} T_{\mathrm{it}}^{\mathrm{M}}\right.$ ax $\left.R_{\mathrm{it}}\right)$ and when it is not $\left(\gamma_{4} R_{\mathrm{it}}\right)$. The low level of learning in average relative earnings (Observation 1$)$ does not exclude learning effects on offer behavior. ${ }^{8}$

The regression result is listed in Table V.1. Overall, our model is highly significant $\left(p<.00001\right.$ and $\left.R^{2}=.7900\right)$ The expected effects in line with Observation 5 are significantly confirmed: $P_{\mathrm{i}, \mathrm{t}}^{\mathrm{M}}$ ax has a negative and highly significant overall effect on offer behavior $\left(\gamma_{1}<0\right)$ in the non-maximal pie-periods and significantly increases offers in the maximal pie-period $\left(\gamma_{1}^{\prime}>0\right)$.

Observation 6 is weakly in line with the regression results since ultimatum power implies only insignificantly smaller offers in $y$-games $\left(\gamma_{3}<0\right)$. Offers increase significantly over time $\left(\gamma_{4}>0\right)$ and decrease only insignificantly when $t$ is the largest pie-period $\left(\gamma_{4}^{\prime}>0\right)$. The latter result is in line with Observation 6 . In case of $A_{\mathrm{it}}^{\mathrm{fter}}=1$ participants, who rejected in the largest pie-period, make a counter offer. Their reactions are captured by parameter $\gamma_{5}$ which is positive and significant. Such counter offers are relatively higher to avoid delaying the agreement even more or not reaching one at all.

\footnotetext{
${ }^{8}$ Participants might have learned to increase their offers and to avoid conflict more often so that on the aggregate level earnings remain stable on average.
} 


\begin{tabular}{|c|c|c|c|c|}
\hline Variables & & $B$. & $t-$ statistic & $p-$ value \\
\hline Constant & $\gamma_{0}$ & -1.081 & -2.142 & .0322 \\
\hline$P_{\mathrm{i}, \mathrm{t}}^{\mathrm{M} \text { ax }}$ & $\gamma_{1}$ & -.0611 & -3.004 & .0027 \\
\hline$P_{\mathrm{i}, \mathrm{ix}}^{\mathrm{M}} \cdot T_{\mathrm{i}, \mathrm{t}}^{\mathrm{M} \text { ax }}$ & $\gamma_{1}^{\prime}$ & .5400 & 57.651 & .0001 \\
\hline$P_{\mathrm{i}, \mathrm{t}} \cdot T_{\mathrm{i}, \mathrm{t}}^{\mathrm{no}} \mathrm{ax}$ & $\gamma_{2}$ & .4878 & 32.506 & .0001 \\
\hline$T_{\mathrm{i}, \mathrm{t}}^{\mathrm{erm}}$ & $\gamma_{3}$ & -.0906 & -1.110 & 2670 \\
\hline$R_{\mathrm{i}, \mathrm{t}}$ & $\gamma_{4}$ & .0114 & 2.603 & .0093 \\
\hline$R_{\mathrm{i}, \mathrm{t}} \cdot T_{\mathrm{i}, \mathrm{t}}^{\mathrm{M} a x}$ & $\gamma_{4}^{\prime}$ & -.0059 & -1.03 & 2990 \\
\hline$A_{\mathrm{it}}^{\mathrm{fter}}$ & $\gamma_{5}$ & 1.841 & 7.231 & .0001 \\
\hline \multicolumn{3}{|l|}{$N=3193^{(9)}$} & \multicolumn{2}{|c|}{$p-$ value $=.00001$} \\
\hline \multirow{2}{*}{\multicolumn{3}{|c|}{$\begin{array}{l}F(7,3185)=1711.75 \\
\text { Adiusted } R^{2}=78955\end{array}$}} & \multicolumn{2}{|l|}{$R^{2}=.7900$} \\
\hline & & & & \\
\hline
\end{tabular}

Table V.1: Estimation results of the regression

Acceptance behavior can be similarly explained by a probit regression in which the dependent variable $y_{\mathrm{it}}$ is coded into $\{0,1\}$ to estimate the probability of acceptance $\left(y_{\text {it }}=1\right.$ ) by subject $i$ in period $t$ with $t=1,2,3$ and $i=1, . ., 35$ (a rejection is coded as $\left.y_{\mathrm{it}}=0\right)$. We denote by $O_{\mathrm{it}}$ the offer to which $y_{\mathrm{it}}$ reacts.

$y_{\mathrm{it}}=\alpha_{0}+\left(\alpha_{1}+\alpha_{1}^{\prime} \cdot T_{\mathrm{it}}^{\mathrm{M} a x}\right) \cdot P_{\mathrm{it}}^{\mathrm{M} a x}+\left(\alpha_{2}+\alpha_{2}^{\prime} \cdot T_{\mathrm{it}}^{\mathrm{M} \text { ax }}\right) \cdot O_{\mathrm{i}, \mathrm{t}}+\alpha_{3} T_{\mathrm{it}}^{\mathrm{erm}}+\left(\alpha_{4}+\alpha_{4}^{\prime} \cdot T_{\mathrm{it}}^{\mathrm{M} \mathrm{ax}}\right) R_{\mathrm{i}, \mathrm{t}}+\alpha_{5} A_{\mathrm{it}}^{\mathrm{fter}}$

The estimation results, as reported in Table V. 2, show that the overall model is significant. The probability of acceptance increases significantly with the offer made $\left(\alpha_{2}>0\right)$ and even more if this is the largest pie period $\left(\alpha_{2}^{\prime}>0\right)$. The highly significant and negative parameter $\alpha_{1}^{\prime}$ reveals that the overall probability of conflict is larger in the largest pie-period: Participants are not simply efficiency minded (see the non-negligible numbers of conflict in Table IV.2) and are more likely to reject in the largest pie-period. According to the positive and significant parameter $\alpha_{5}$ they later on are more inclined to accept later on. Ultimatum power helps to reach an agreement $\left(\alpha_{3}>0, p\right.$-level $\left.=.0001\right)$, confirming Observation 6. Over time, the probability of acceptance decreases significantly, that is responders learn to reject.

\footnotetext{
${ }^{9}$ Our regression takes 3193 observations into account instead of the 5040 theoretical ones due to agreements in earlier periods (for $t<2$ and $t<3$ ).
} 


\begin{tabular}{|c|c|c|c|c|c|}
\hline & $B$ & S.E. & $t-$ ratio & $p-$ value \\
\hline Constant & $\alpha_{0}$ & -1.5740 & .431 & -3.649 & .0003 \\
\hline$P_{\mathrm{it}}^{\mathrm{M} \text { ax }}$ & $\alpha_{1}$ & -.0230 & .015 & -1.425 & .1542 \\
\hline$P_{\mathrm{it}}^{\mathrm{Max}} \cdot T_{\mathrm{it}}^{\mathrm{Max}}$ & $\alpha_{1}^{\prime}$ & -.1214 & .014 & -8.627 & .0001 \\
\hline$O_{\text {it }}$ & $\alpha_{2}$ & 1361 & .018 & 7.481 & .0001 \\
\hline$O_{\mathrm{it}} \cdot T_{\mathrm{it}}^{\mathrm{Max}}$ & $\alpha_{2}^{\prime}$ & .4082 & .036 & 11.202 & .0001 \\
\hline$T_{i, t}^{e r m}$ & $\alpha_{3}$ & .2745 & .067 & 4.058 & .0001 \\
\hline$R_{\text {it }}$ & $\alpha_{4}$ & -.0133 & .004 & -3.057 & .0022 \\
\hline$R_{\mathrm{it} .} T_{\mathrm{it}}^{\mathrm{Max}}$ & $\alpha_{4}^{\prime}$ & .0094 & .005 & 1.859 & .0630 \\
\hline$A_{\mathrm{it}}^{\text {t ter }}$ & $\alpha_{5}$ & 1.792 & .160 & 11.178 & .0001 \\
\hline $\log L=-92$ & 2.267 & & $p-l$ & vel $=.0001$ & \\
\hline$\chi^{2}=2563.6$ & & & $N^{(10}$ & $=3193$ & \\
\hline
\end{tabular}

Table V.2: Estimation results of Probit Regression Model

\section{Discussion and conclusions}

In typical experiments of alternating offer bargaining participants are confronted with just one pie-development and (except for Güth, Ockenfels and Wendel, 1993) with ultimatum power only in the last period $t=T$. Compared to this, our participants faced four very different types of pie-dynamics as well as early $(t \leq T)$ and only late $(t=T)$ ultimatum power. By exploring the broader spectrum of institutions/rules we could demonstrate that participants

- are motivated by efficiency considerations, i.e. aim at reaching an agreement when the pie is largest, and

- use unfair offers mainly as a signal that an agreement should be reached when the pie is largest,

- are reluctant to exploit ultimatum power regardless of when it is available.

\footnotetext{
${ }^{10}$ Cf. note 2 .
} 
Compared to other studies of robust learning (see Güth, 2000) this leaves little or no room for learning. This suggests the more general conclusion that experience or learning, that is the shadow of the past, is less important when strong norms like efficiency and equality concerns provide strong guidance on how to negotiate.

Forward-looking deliberation seems to be decisive. The main intentions, namely to share the maximal pie and to propose a rather fair distribution, reveal carefully deliberated plans and thus a much stronger shadow of the future than of the past. The results for the games $I^{\mathrm{y}}$ and $H^{\mathrm{y}}$ nevertheless reveal that normative game theory, which is purely forward-looking, does not explain experimentally observed behavior (compare the predictions in Table II.2 with the results in Table IV.4). The forward-looking considerations of the participants are strategic rather than norm-oriented: Behavior is shaped by fairness and efficiency concerns and not by opportunistic rationality.

It would, however, be premature to generalize our conclusions beyond the scope of distribution conflicts in small groups like dyads. Other situations, for instance large anonymous markets, might trigger more egoistic motives and lead to outcomes which are more in line with opportunistic rationality. Although each robust learning experiment like ours already covers a variety of structurally different institutions, one should conduct similar studies for other types of decision problems (see the studies reviewed in Güth, $2000)$.

When can we nevertheless expect external validity of our major findings? Although we did not try to induce entitlement (see, e.g. Hoffman and Spitzer, 1995, or Güth and Tietz, 1986), we expect strong fairness concerns when there exists strong entitlement of a qualitative nature. Imagine, for instance, a joint venture of two partners who contribute various skills and talents in addition to their time and capital. It seems rather likely that such partners when trying to terminate their joint venture, for instance by selling it, will sell when they achieve the highest price (their pie), and that this price will be shared equally. Furthermore, the social norms of fairness and efficiency will be especially dominant when future dealings among the partners cannot be excluded. 


\section{References}

[1] Binmore, K., A. Shaked, and J. Sutton (1985): Testing noncooperative bargaining theory: A preliminary study, American Economic Review, 75 (5), 1178-1180.

[2] Güth, W. (1995): On ultimatum bargaining - A personal review, Journal of Economic Behavior and Organization, 27, 329-344.

[3] Güth, W. (2000): Robust learning experiments - Evidence for learning and deliberation, Working Paper, Humboldt University of Berlin.

[4] Güth, W., R. Schmittberger, and B. Schwarze (1982): An experimental analysis of ultimatum bargaining, Journal of Economic Behavior and Organization, 367-388.

[5] Güth, W. and R. Tietz (1986): Auctioning ultimatum bargaining positions - How to act if rational decisions are unacceptable?, in: Current Issues in West German Decision Research, R.W. Scholz (ed.), Frankfurt, 173-185.

[6] Güth, W., P. Ockenfels, and M. Wendel (1993): Efficiency by trust in fairness? - Multiperiod ultimatum bargaining experiments with an increasing cake, International Journal of Game Theory, 22, 51-73.

[7] Harsanyi, J.C. and R. Selten (1972): A Generalized Nash Solution for Two-Person Bargaining Games with Incomplete Information, Management Science, 18 (5)Part $2,80-106$.

[8] Hoffman, E. and M.L. Spitzer (1985): Entitlement, Rights, and Fairness: An Experimental Examination of Subjects' Concepts of Distributive Justice, Journal of Legal Studies, 14, 259-297.

[9] Huck, S., H.-T. Normann, and J. Oechssler (1999): The indirect evolutionary approach to explaining fair allocations, Games and Economic Behavior 28, 13-24.

[10] Kohlberg, E. and J.F. Mertens (1986): On the Strategic Stability of Equilibria, Econometrica, 54, 1003-1039. 
[11] McKelvey, R. D. and T. R. Palfrey (1992): An experimental study of the centipede game, Econometrica, 60, 803-836.

[12] Neelin, J., H. Sonnenschein, and M. Spiegel (1988): A further test of noncooperative bargaining theory: Comment, American Economic Review, 78 (4), 824-836.

[13] Ochs, J. and A. E. Roth (1989): An experimental study of sequential bargaining, American Economic Review, 79 (3), 355-384.

[14] Roth, A. E., Erev, I. (1995): Learning in Extensive-Form Games : Experimental Data and Simple Dynamic Models in the Intermediate Term, Games and Economic Behavior, vol.8, pp. 164-212.

[15] Roth, A. E. (1995): Bargaining experiments, in: Handbook of Experimental Economics, J. H. Kagel and A. E. Roth (eds.), Princeton, N.J.: Princeton University Press, 253-348.

[16] Rubinstein, A. (1982): Perfect equilibrium in a bargaining model, Econometrica, 50, 97-109.

[17] Rubinstein, A. (1985): A Bargaining Model with Incomplete Information about Time Preferences, Econometrica, 53, 1151-1172.

[18] Selten, R. (1975): Reexamination of the Perfectness Concept for Equilibrium Points in Extensive Games, International Journal of Game Theory, 4 (1), 25-55; reprinted in H.W. Kuhn (ed.), Classics in Game Theory, Princeton University Press, 1997, $317-54$.

[19] Weg, E., A. Rapoport, and D. S. Felsenthal (1990): Two-person bargaining behavior in fixed discounting factors games with infinite horizon, Games and Economic Behavior, 2 (1), 76-95.

[20] Weibull, J.W. (1995): Evolutionary game theory, Cambridge and London: MIT Press. 


\section{Appendix A: Instructions:}

In the experiment you will interact anonymously in groups of two participants. Each participant gets DM 5.0 show up fee. You will not be informed about the other's identity, nor will your partner be informed about yours. You and your partner constitute a group of two persons named $A$ and $B$. What $A$ and $B$ can share is an amount of points, $p(20$ points $=\mathrm{DM}$ 1.0), whose value depends on when you and you partner reach an agreement. The interaction is organized as follows:

1. In the first period, $t=1$, Partner $A$ chooses an offer $O_{1}$ to Partner $B$. If Partner $B$ accepts the offer, $A$ earns $p_{1}-O_{1}$ and $B$ earns $O_{1}$. If not, they proceed to the second period $t=2$.

2. In the second period, $t=2$, Partner $B$ chooses an offer $O_{2}$ to Partner $A$. If Partner $A$ accepts the offer, $B$ earns $p_{2}-O_{2}$ and $A$ earns $O_{2}$. If not, they proceed to the third period $t=3$.

3. In the third period, $t=3$, Partner $A$ chooses an offer $O_{3}$ to Partner $B$. If Partner $B$ accepts the offer, $\mathrm{A}$ earns $p_{3}-\mathrm{O}_{3}$ and $\mathrm{B}$ earns $\mathrm{O}_{3}$. If not, both earn 0 .

The values $p_{1}, p_{2}$ and $p_{3}$ depend on the situation $D, I, H$ or $V$ :

\begin{tabular}{|c|c|c|c|}
\hline$p_{1}$ & $p_{2}$ & $p_{3}$ & Situation \\
\hline 30 & 20 & 10 & $D$ \\
\hline 10 & 20 & 30 & $I$ \\
\hline 10 & 25 & 10 & $H$ \\
\hline 25 & 10 & 25 & $V$ \\
\hline
\end{tabular}

In addition, you may have a Termination Option.

Termination Option : If one partner chooses the termination option in period $t<3$, the interaction process ends with this offer, i.e. the other cannot make a counter-offer. Partner 
$A$ can choose the Termination Option in $t=1$, and partner $B$ in $t=2$. If $A$ chooses the termination option, partner $B$ cannot choose it in the next period as the interaction stops in period $t=1$ regardless of whether $B$ accepts or not.

You will be four times in situation $D$ (twice without and twice with the Termination Option), then four times in situation $I$ (twice without and twice with the Termination Option), then four times in situation $H$ (twice without and twice with the Termination Option), four times in situation $V$ (twice without and twice with the Termination Option). The whole session consists of three sequences of such 16 rounds, i.e. of altogether 48 rounds. At the beginning of each round, we randomly form new groups of two participants with one $A$ and one $B$ participant.

After each round you will be informed about your own earnings. Payments will be made privately at the end of the session. Please raise your hand if you have any questions. We will try to answer them privately. Thank you for your cooperation!

\section{Appendix B: Questionnaire}

Please fill out this questionnaire completely. To check your understanding of the instructions, we kindly ask you to answer the following questions. Consider the following arbitrarily specified decisions:

1. $A$ and $B$ didn't reach an agrement in period $t=1$. Who will propose a counter-offer in period $t=2$ ?

$A$ or $B$

2. In period $t=2$, the offer equals $O_{2}=5$ and $A$ accepts it. How much do $A$ and $B$ participants earn?

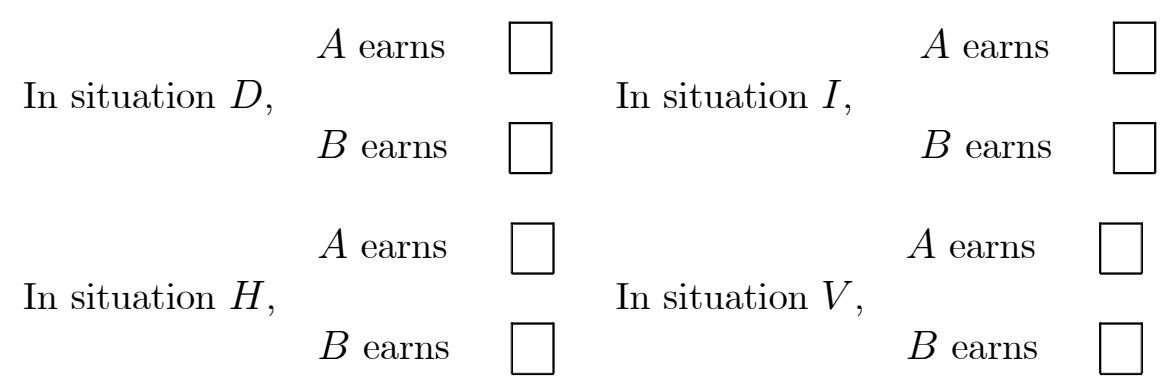


3. Imagine that partner $A$ chooses the termination option in period $t=1$. Can Partner $B$ make a counteroffer in period $t=2$ ? 